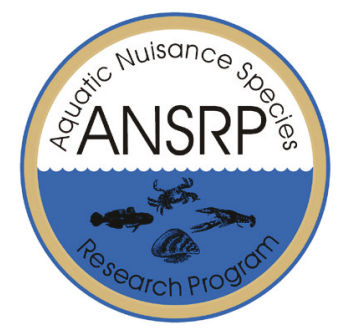

\title{
Maximum Swim Speed of Migrating Sea Lamprey (Petromyzon marinus): Reanalysis of Data from a Prior Study
}

by Jan Jeffrey Hoover and Catherine E. Murphy

PURPOSE: Evaluate $4 \mathrm{~m} / \mathrm{sec}$ target water velocity suggested for hydraulic containment of migrating adult Sea Lamprey.

OBJECTIVES: This study was designed to do the following:

1. Review all available information on swimming performance of Sea Lamprey

2. Identify and reanalyze the most extensive data available

BACKGROUND: Sea Lamprey (Petromyzon marinus) are predatory and destructive animals superficially similar to fish (Figure 1); however, Sea Lamprey lack a well-developed boney skeleton, jaws, and paired fins and, as a result, are classified separately from true fishes (Moyle and Cech 1982). History, impacts, and management of invasive populations in the Great Lakes are well documented (Cox 1999; Rapai 2016; Egan 2017). Construction of the Erie Canal in 1825 and the Welland Canal in 1831 connected, respectively, the Hudson River and the Lake Ontario-St. Lawrence River to Lake Erie, and provided Sea Lamprey in the North Atlantic access to the upper Great Lakes previously isolated by Niagara Falls. Lamprey were subsequently detected in Lake Erie in 1921, Lake Michigan in 1936, Lake Huron in 1937, and Lake Superior in 1938. By 1946, lamprey populations were abundant and stocks of native salmonids and whitefishes had declined due to predation. Control programs were initiated in the 1950s and continue at present. These programs use combinations of traps, pheromones, lampricides, reproductive sterilization of adults, and physical barriers to reduce or prevent successful migration, reproduction, and recruitment of lamprey in their natal tributary streams. Barriers may be electric fields, simple dams (or sieves), vertical drops, or areas of fast-flowing water.

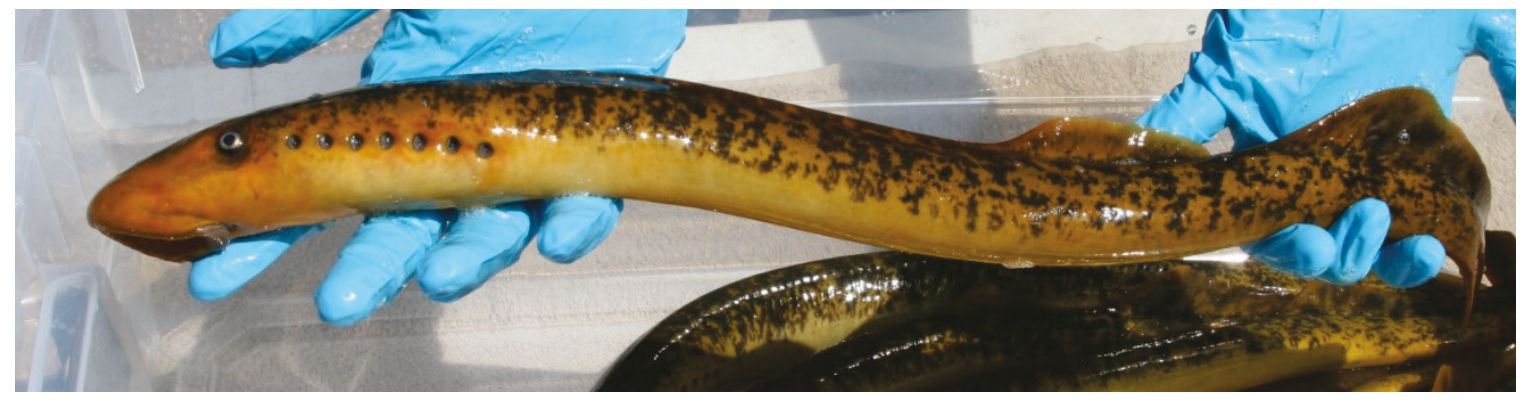

Figure 1. Mature Sea Lamprey (Petromyzonus marinus) from the Manistique River, MI. 
High water velocities contain populations of Sea Lamprey naturally and are sometimes proposed as safe, cost-effective barriers (Hunn and Youngs 1980; Lavis et al. 2003). Velocities of approximately $4 \mathrm{~m} / \mathrm{sec}$ are believed to exceed burst swim speeds of adult migratory Sea Lamprey and, if so, should effectively contain them from moving upriver to spawn. Two studies support this contention. Hanson (1980) demonstrated that no lamprey tested at velocities of $3.96 \mathrm{~m} / \mathrm{sec}$ successfully traveled the entire distance of a 3.3 meter-long flume. McAuley (1996) showed that predicted endurance (timeto-fatigue) should be $<2 \mathrm{sec}$ at this swim speed (Figure 2). Both of these studies, however, are limited in their ability to predict maximum swim speed of Sea Lamprey. The former study relied on volitional swimming, with most animals remaining at a single location in the flume. The latter study challenged lamprey to swim but did not test at speeds $>3.25 \mathrm{~m} / \mathrm{sec}$. In addition, certain aspects of the methodologies may have obscured natural swimming and station-holding behavior, making comparisons among studies tenuous.

McAuley (1996) presented original data from his own research, data from three other studies (Beamish 1974; Hanson 1980; Bengstedt et al. 1981), and a series of regression models, some based on his data only and others on his data combined with that of Beamish (1974). These regression models should be interpreted and applied with caution. Combining data was inappropriate because the small, nonmigratory, young predators studied by Beamish are physically and physiologically disparate from the large, migratory, non-feeding sexually mature adults studied by McAuley. The curvilinear model is different in shape (and assumptions) from the log-linear and piecewise (or "broken-stick") regression models proposed and supported in most swim studies of migratory fishes (e.g., Castro-Santos 2005). Highest water velocities tested were substantially lower $(<3.25 \mathrm{~m} / \mathrm{sec})$ than the target velocity $(4 \mathrm{~m} / \mathrm{sec})$. Differences in experimental methodologies and available data among the studies were substantial (Table 1). Lastly, no estimates of variation (e.g., confidence limits, prediction limits) are provided for the models. McAuley explicitly acknowledged differences between the studies and variation within his own data, and also provided his raw data in two appendices. These data are extensive and sufficiently robust to allow independent and alternative analysis.

METHODS: An ordinary least squares regression (OLS) was performed on $\log _{10}$-transformed endurance $(\mathrm{sec}+1)$ values vs. water velocity $(\mathrm{m} / \mathrm{sec})$ provided in appendices B2 and C4 of McAuley (1996) using SAS software (v9.4, SAS Institute, Cary, NC). Multiple regression analysis was also performed to evaluate influence of water temperature and lamprey size on endurance.

RESULTS: The log-linear regression model (Figure 3) was significant $\left(\mathrm{F}_{1,295}=414.59, \mathrm{p}=<.0001\right)$ with $\mathrm{R}_{\text {adj }}^{2}=0.5829$ and model parameters as follows:

\section{$\log _{10}$ Endurance $=1.79323-0.42278($ Water Velocity $)$}

Model residuals were normally distributed (Figure 4; Shapiro-Wilk W=0.9952, $\mathrm{p}=0.4798$ ) and showed no nonlinear trends with the regressor (Figure 5). Piecewise regression was attempted using various inflection points, but none were statistically significant. Therefore, the log-linear relationship was deemed appropriate for these data. 


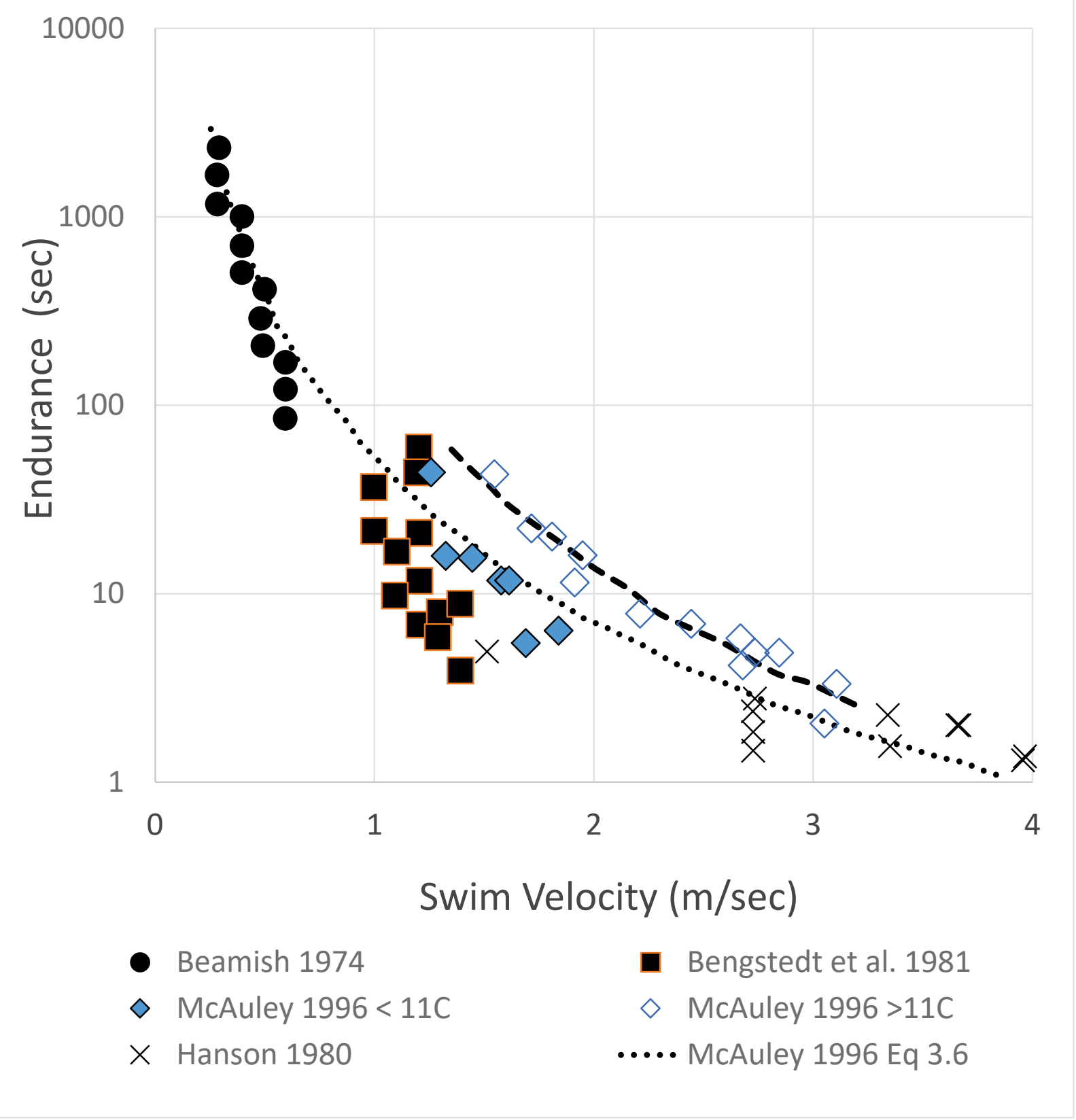

Figure 2. Endurance curves for Sea Lamprey based on original data by McAuley 1996 (diamonds), compared to three previous studies (circles, squares, $x$ 's). This figure was created by digitizing a photocopy of Figure 3.7 in McAuley's dissertation using WebPlotDigitizer Version 3.11 (Rohatgi 2015). 
ERDC/TN ANSRP-18-1

February 2018

\section{Table 1. Sea Lamprey swimming performance studies.}

\begin{tabular}{|l|l|l|l|l|l||l||}
\hline \hline $\begin{array}{l}\text { Number } \\
\text { of Trials }\end{array}$ & $\begin{array}{l}\text { TL } \\
(\mathbf{m m})\end{array}$ & $\begin{array}{l}\text { Water } \\
\text { Temperature } \\
\left({ }^{\circ} \mathbf{C}\right)\end{array}$ & Life Stage & $\begin{array}{l}\text { Test } \\
\text { Chamber }\end{array}$ & Data Available & Reference \\
\hline 160 & $123-148$ & $5,10,15$ & Feeding & Tunnel & $\begin{array}{l}\text { Numerical } \\
\text { models }\end{array}$ & Beamish, 19741 \\
\hline 12,19 & $285-567$ & $11.4-23.0$ & Migratory & Flume & $\begin{array}{l}\text { Group trials and } \\
\text { Individual Trials }\end{array}$ & Hanson, 1980² \\
\hline 30 & $420-545$ & 6,10 & Migratory & Tunnel & "Group trials” & $\begin{array}{l}\text { Bengston et al., } \\
1981^{3}\end{array}$ \\
\hline 297 & $390-590$ & $9.0-21.1$ & Migratory & Flume & Individual trials & McAuley, 19964 \\
\hline
\end{tabular}

${ }^{1}$ Beamish (1974) tested each lamprey individually after it had fasted 4 days.

${ }^{2}$ Hanson (1980) tested lamprey passage in groups of 24-51 but conducted 19 tests of endurance by individual lamprey.

${ }^{3}$ Bengston et al. (1981) tested and retested the same 10 lamprey, one at a time, in replicates of 1-10. For each series of data, a single representative value (presumably some measure of central tendency) was reported.

${ }^{4}$ McAuley (1996) tested lamprey individually.

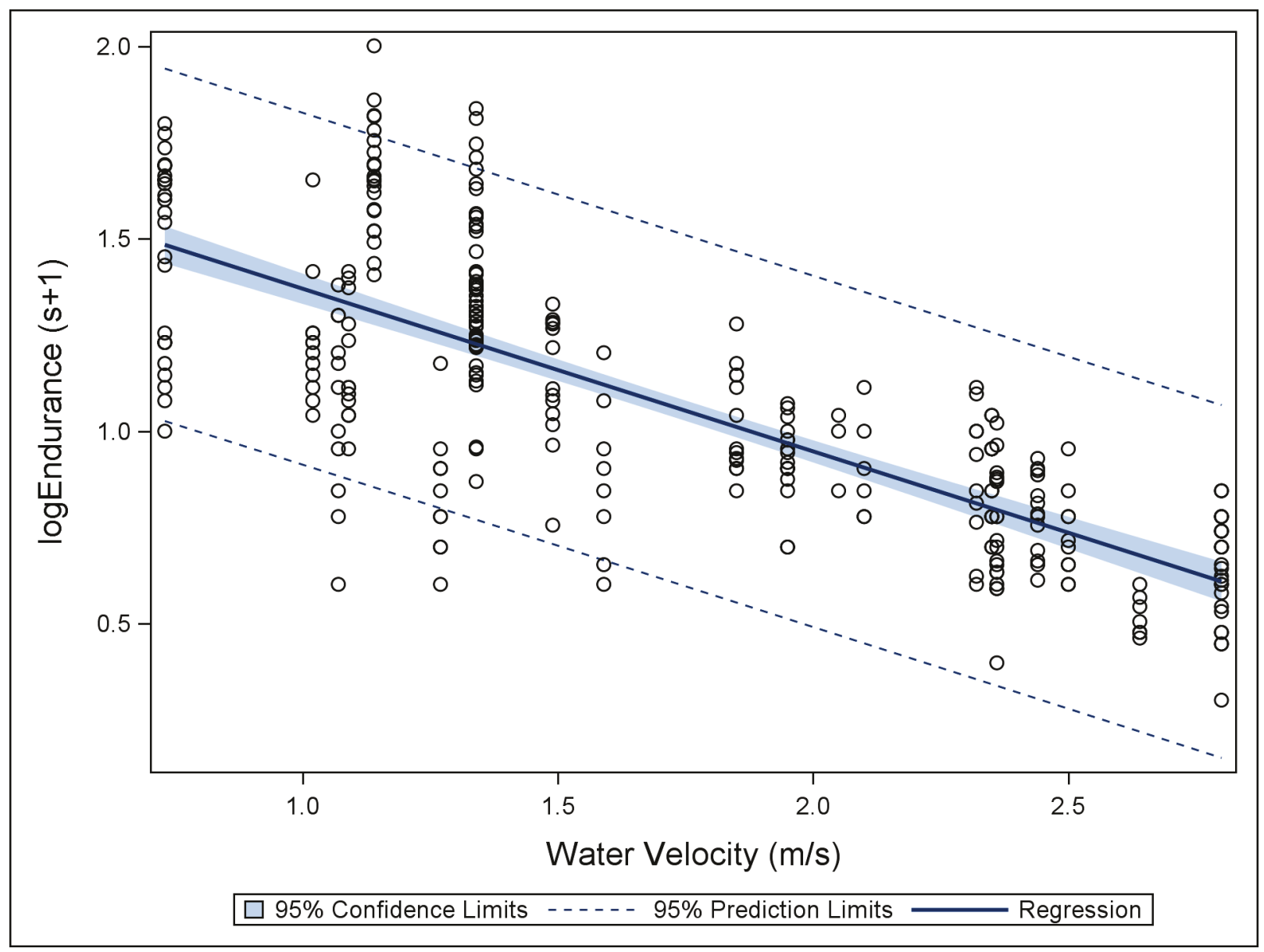

Figure 3. Log-linear regression model for swimming endurance of Sea Lamprey. Data source: McAuley 1996. 


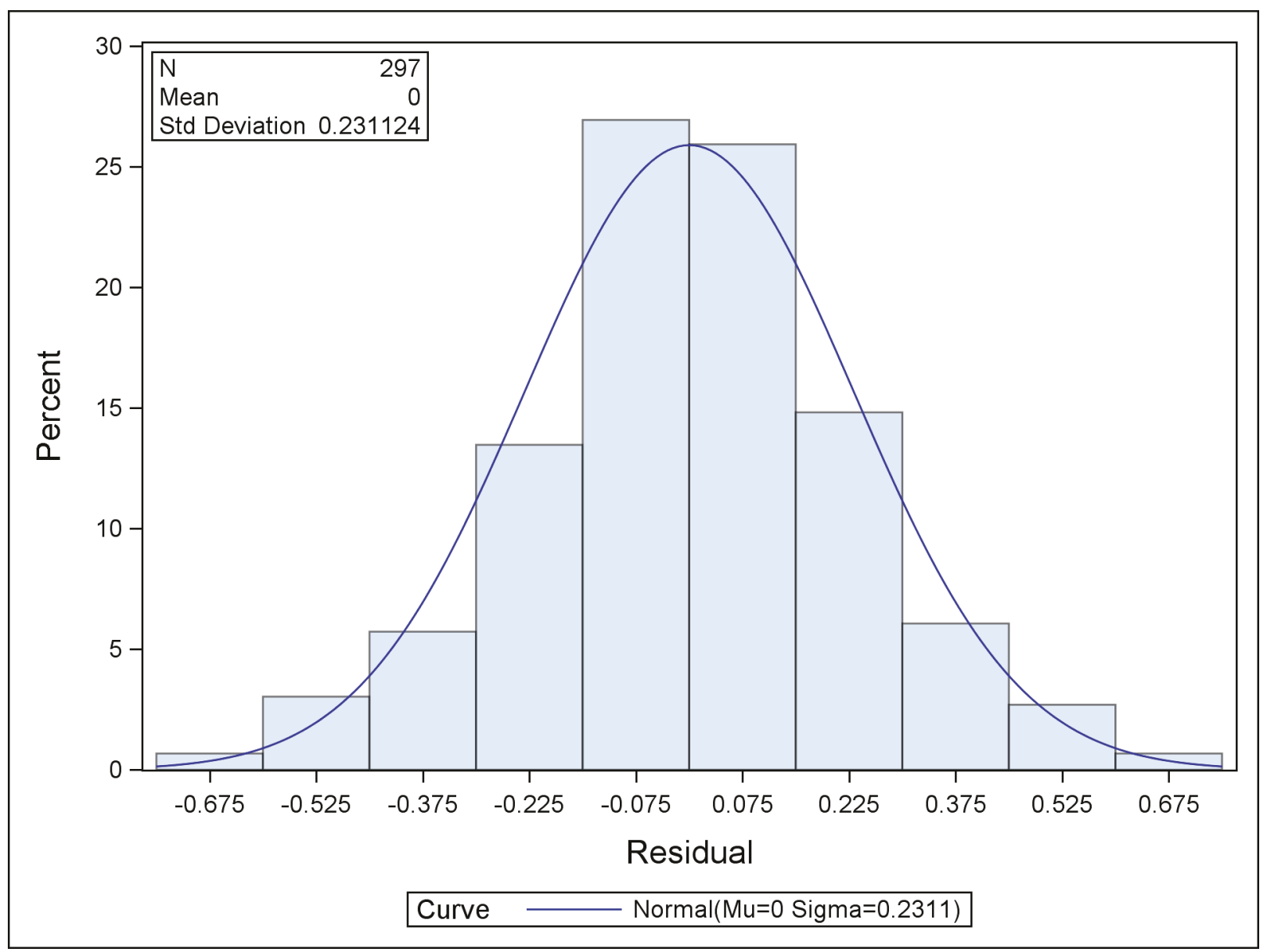

Figure 4. Distribution of residuals for the log-linear regression model. Data source: McAuley 1996.

Asymmetrical 95\% confidence interval about x-intercept was estimated using the method of Draper and Smith (1998).

$$
\mathrm{X} \text {-intercept }=4.2416,95 \% \mathrm{CI}=(\mathbf{4 . 0 1 1 2}, \mathbf{4 . 5 1 9 5 )}
$$

Error on the regression, however, was heteroscedastic (uneven) with more scatter on the left side and less on the right side (Figure. 3 and Figure. 5). This violates the homogeneity of variance assumption for OLS regression. To validate statistical tests of significance in the presence of heteroscedasticity, regressions were rerun using White's variance-covariance matrix to obtain consistent standard errors of the parameter estimates. Differences in results were negligible. Standard errors changed slightly but parameter estimates and t-tests produced the same results. Confidence limits about the $\mathrm{x}$ intercept were comparable to the original model: $4.0084,4.5160$. 


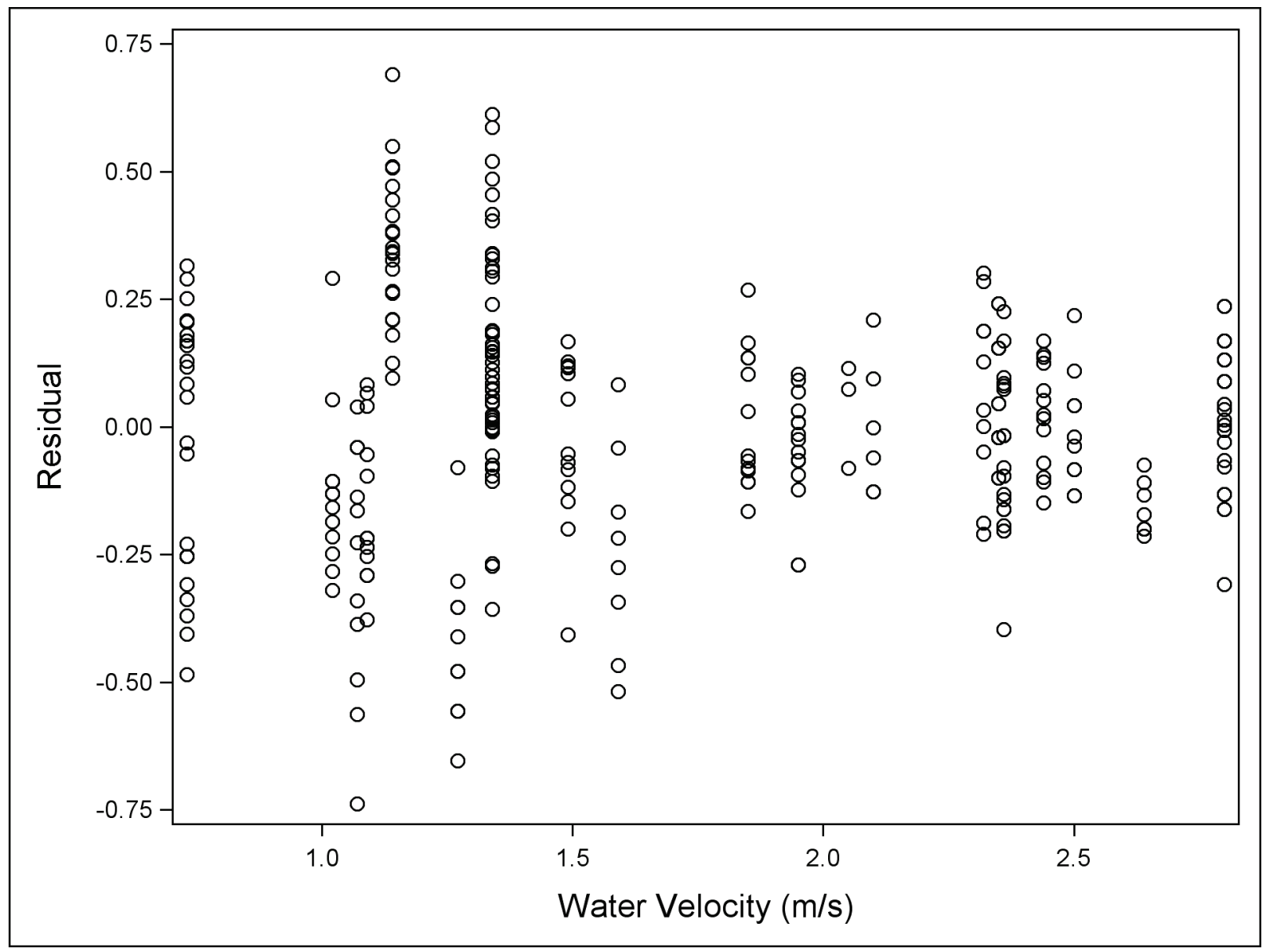

Figure 5. Scatter plot of residuals associated with each of the water velocities tested.

Multiple regression analysis revealed that total length of lamprey (TL in $\mathrm{mm}$ ) and water temperature $\left({ }^{\circ} \mathrm{C}\right.$ ) also may have affected swimming endurance (Table 2 ). Regression coefficients for both TL and temperature were statistically significant and accounted for $1.8 \%$ and $9.5 \%$ of the total variation, respectively. Water velocity and water temperature were moderately correlated (Pearson Rho=0.77619, $\mathrm{p}<.0001)$, however.

\section{Table 2. Results of multiple regression analysis.}

\begin{tabular}{|c|c|c|c|c|c|c|c|}
\hline \multicolumn{8}{|c|}{ Multiple Regression Parameter Estimates } \\
\hline Variable & DF & $\begin{array}{l}\text { Parameter } \\
\text { Estimate }\end{array}$ & \begin{tabular}{|l} 
Standard \\
Error
\end{tabular} & t Value & $\operatorname{Pr}>|\mathbf{t}|$ & \begin{tabular}{|l|} 
Squared \\
Semi-partial \\
Corr Type I
\end{tabular} & $\begin{array}{l}\text { Variance } \\
\text { Inflation }\end{array}$ \\
\hline Intercept & 1 & 0.63551 & 0.16510 & 3.85 & 0.0001 & & 0 \\
\hline Water Velocity (m/sec) & 1 & -0.63105 & 0.02809 & -22.47 & $<.0001$ & 0.59199 & 2.56280 \\
\hline $\mathrm{TL}(\mathrm{mm})$ & 1 & 0.00170 & 0.00030580 & 5.57 & $<.0001$ & 0.01798 & 1.02361 \\
\hline Water Temperature ( C ) & 1 & 0.04365 & 0.00452 & 9.65 & $<.0001$ & 0.09501 & 2.59799 \\
\hline
\end{tabular}

DISCUSSION: The log-linear model results presented herein (Figure 3) indicate maximum swim speeds of 4.0-4.5 m/sec (based on confidence interval around the $\mathrm{x}$-intercept), higher than that suggested by the curvilinear model of McAuley of $4 \mathrm{~m} / \mathrm{sec}$ (based on apparent endpoint). Models 
developed by McAuley, however, have high $\mathrm{R}^{2}$ values (i.e., $\mathrm{R}^{2}=0.90-0.94$ ) that do not reflect point scatter of the individual raw data (Figure 2), and which do not provide representative estimates of variation suggesting that they may have been based on aggregated data (e.g., mean values). The model presented here realistically reflects variation in endurance, some of which is attributable to variation in water temperature and size of lamprey. Both factors positively influence endurance at any water velocity.

McAuley addressed these sources of variation by parsing data and developing separate regressions. He presents separate endurance curves for low and high temperature ranges (Figure 1) and for lamprey that were 400 and $500 \mathrm{~mm}$ TL (p. 55, Figure 3.9 in McAuley 1996). The multiple regression model here (Table 2), based on all data, provides a single model that will predict endurance for lamprey within the range of water velocities and sizes tested (Table 1).

Data from these swimming performance studies must be viewed as conservative estimates of lamprey endurance, though, because they imposed behavioral constraints on locomotion and station-holding in the lamprey tested. Specifically, mesh liners used in test chambers prevented lamprey attachment to the substrate, forcing the animals to free-swim for unnaturally extended periods of time, presumably in a single bout, which would accelerate time-to-fatigue (Beamish 1974; Bengstedt et al. 1981; McAuley 1996). This is highly unnatural for swimming vertebrates, which typically employ energy-conserving behaviors (e.g., hunkering, tail-bracing, oral grasping) to recover from fatigue during sequential bouts at moderate to high speeds (Adams et al. 2003). Resting in place, even for short durations ( $<1 \mathrm{~min}$ ), can extend endurance substantially (e.g., by more than a factor of 4), presumably by providing some recovery from oxygen debts incurred from anaerobic exercise (Adams et al. 2000). Because lamprey frequently rest while attached to the substrate, values higher than $4.0-4.5 \mathrm{~m} / \mathrm{sec}$ should be considered as alternative targets, providing greater likelihood of containment.

Relative swim speeds can also be used to provide an alternative upper limit on water velocities. In a review of swimming performance of fishes, maximum swim speed approximated 10 body lengths per second or BL/sec (Videler and Wardle 1991). Using this rule of thumb, maximum swim speed of a large $580 \mathrm{~mm}$ TL lamprey would be $5.8 \mathrm{~m} / \mathrm{sec}$. This could be an overestimate. Anguilliform swimmers (i.e., vertebrates using full-body undulations), like eels and lamprey, are typically slower swimmers than subcarangiform or carangiform swimmers (i.e., vertebrates using posterior undulations), like trout, which predominated in the review. Hanson (1980), however, showed that lamprey were capable of swimming up to $5 \mathrm{sec}$ in water velocities of $3.96 \mathrm{~m} / \mathrm{sec}$. Lamprey tested at this speed averaged $416-480$ $\mathrm{mm}$, which means they were swimming up to $8.2-9.5 \mathrm{BL} / \mathrm{sec}$. A $580 \mathrm{~mm}$ TL lamprey swimming at the same relative speed then would be capable of moving up to $4.8-5.5 \mathrm{~m} / \mathrm{sec}$.

In summary, the putative upper limit on water velocity of approximately $4 \mathrm{~m} / \mathrm{sec}$ first identified by Hanson (1980) and later supported by the curvilinear model of McAuley (1996) was slightly lower than the range of 4.0-4.5 m/sec estimated from our log-linear model of the latter's data. Restricted range of raw data (i.e., water velocities $0.73-2.80 \mathrm{~m} / \mathrm{sec}$ ) and methodological constraints on lamprey behavior (i.e., prevention of station-holding), suggest that these numbers could be underestimates for lamprey swimming in faster water under natural conditions. Relative swim speeds documented by Hanson suggest that large adult lamprey are capable of making limited movements in water velocities of approximately $5 \mathrm{~m} / \mathrm{sec}$. 
ACKNOWLEDGMENTS: Impetus for this study was provided during interagency discussion of a proposed Sea Lamprey barrier in the Grand River, MI. Analyses and report preparation were funded by the Aquatic Nuisance Species Research Program (ANSRP). Copies of unpublished completion reports were provided by Jessica Barber, United States Fish and Wildlife Service. Permission to publish was granted by the Chief of Engineers.

ADDITIONAL INFORMATION: For additional information, contact Dr. Jan Jeffrey Hoover (601) 634-3996, Jan.J.Hoover@usace.army.mil, or the manager of the Aquatic Nuisance Species Research Program (ANSRP), Dr. Linda Nelson, (601) 634-2656, Linda.S.Nelson@usace.army.mil.

This technical note should be cited as follows:

Hoover, J. J. and C. E. Murphy. 2018. Maximum swim speed of migrating Sea Lamprey (Petromyzon marinus): reanalysis of data from a prior study. ERDC/TN ANSRP-18-1. Vicksburg, MS: U.S. Army Engineer Research and Development Center. http://el.erdc.usace.army.mil/ansrp/ansrp.html

\section{REFERENCES}

Adams, S. R., G. L. Adams, and J. J. Hoover. 2003. Oral grasping: a distinctive behavior of cyprinids for maintaining station in flowing water. Copeia 2003(4): 851-857.

Adams, S. R., J. J. Hoover, and K. J. Killgore. 2000. Swimming performance of the Topeka shiner (Notropis topeka) an endangered Midwestern minnow. Am. Mid. Nat. 144(1): 178-186.

Beamish, F. W. H. 1974. Swimming performance of adult Sea Lamprey, Petromyzon marinus, in relation to weight and temperature. Trans. Am. Fish. Soc. 103(2): 355-358.

Bengstedt, R. A., D. V. Rottiers, and N. R. Foster 1981. Laboratory determination of maximum swimming speed of migrating Sea Lampreys: a feasibility study. Administrative Report 81-3. Ann Arbor, MI: Great Lakes Fishery Laboratory, US Fish and Wildlife Service.

Castro-Santos, T. 2005. Optimal swim speeds for traversing velocity barriers: an analysis of volitional high-speed swimming behavior of migratory fishes. J. Exp. Biol. 208(3): 421-432.

Cox, G. W. 1999. Alien species in North America and Hawaii - impacts on natural ecosystems. Washington, DC and Covelo, CA: Island Press.

Draper, N. R. and Smith, H. 1998. Wiley series in probability and statistics, in applied regression analysis, third edition. Hoboken, NJ: John Wiley \& Sons, Inc..

Egan, D. 2017. The death and life of the Great Lakes. New York, NY: W.W. Norton and Co.

Hanson, L. H. 1980. 1980 study to determine burst swimming speed of spawning-run Sea Lampreys (Petromyzon marinus). Research Completion Report, Hammond Bay Biological Station. Millersburg, MI: US Fish and Wildlife Service.

Hunn, J. B. and W. D. Youngs. 1980. Role of physical barriers in the control of Sea Lamprey (Petromyzon marinus). Can. J. Fish. Aquat. Sci 37: 2118-2122.

Lavis, D. S., A. Hallett, E. M. Koon, and T. McAuley. 2003. History of and advances in barriers as an alternative method to suppress Sea Lampreys in the Great Lakes. J. Great Lakes Res. 29(Supplement 1): 362-372.

McAuley, T. C. 1996. Development of an instream velocity barrier to stop Sea Lamprey (Petromyzon marinus) migrations in Great Lake streams. MS thesis, University of Manitoba, Winnipeg, Canada.

Moyle, P. B. and J. J. Cech, Jr. 1982. Fishes: an introduction to ichthyology. Prentice-Hall, Inc., Englewood Cliffs, NY. 
Rapai, W. 2016. Lake invaders - invasive species and the battle for the future of the Great Lakes. Detroit, MI: Wayne State University Press.

Rohatgi, A. 2015. WebPlotDigitizer user manual 3.9. 23 pp. Available at: http://arohatgi.info/WebPlotDigitizer/

Videler, J. J. and C. S. Wardle. 1991. Fish swimming stride by stride: speed limits and endurance. Rev. Fish Biol. Fish. 1(1): 23-40.

NOTE: The contents of this technical note are not to be used for advertising, publication, or promotional purposes. Citation of trade names does not constitute an official endorsement or approval of the use of such products. 